\title{
O contador de estórias em tempos modernos: considerações sobre o narrador de estórias no projeto estético-literário de João Guimarães Rosa
}

\author{
Sarah Forte \\ Universidade Federal do Ceará
}

\begin{abstract}
Resumo:
Este trabalho objetiva tecer considerações sobre o contador de estórias no projeto estético-literário de Guimarães Rosa. Para tanto, procederemos a uma breve revisão da crítica rosiana, destacando clichês, para, a seguir, aprofundarmo-nos em aspectos desse projeto, como a noção de regionalismo deste autor, o seu trabalho com a linguagem e a figura do contador de estórias, de matriz oral, que será por nós interpretada como um narrador atuante em tempos modernos. Faremos uso da figura de diversos contadores de estórias que surgem em obras de João Guimarães Rosa, nos fixando em especial nas novelas "Buriti" e "Cara-de-bronze". Nosso objeto de estudo configura-se basicamente como uma indagação: que faz a ancestral figura do contador de estórias em uma narrativa moderna? Nossas considerações desejam oferecer trilhas, pistas, para se compreender o lugar que ocupa a categoria contador de estórias nos textos de Rosa, categoria essa haurida da literatura oral.
\end{abstract}

Palavras-chave: João Guimarães Rosa; linguagem; estória.

"[...] só se pode entrar no mato é até ao meio dele. Assim, esta estória."

A frase em epígrafe plasma a noção de leitura que a prosa de João Guimarães Rosa proporciona. Para compreender aspectos basilares da prosa deste autor, deve-se investigar o projeto estético-literário que enforma sua escrita. Conhecido como um alquimista da língua, um escritor de extrema criatividade, o autor de Grande sertão: veredas firma-se no panorama literário brasileiro como literato que reinventou nosso idioma.

Este artigo tece considerações sobre o narrador de estórias no projeto estéticoliterário de Rosa. Para tanto, procede a uma breve revisão da fortuna crítica rosiana,

\footnotetext{
${ }^{1}$ ROSA. No Urubuquaquá, no Pinhém, p. 103.
} 
destacando certos clichês, ${ }^{2}$ para, a seguir, aprofundar-senos em certos aspectos desse projeto, como a peculiar noção de regionalismo deste autor, e a figura do contador de estórias que, não por acaso, será interpretada como um narrador que atua em tempos modernos. Serão utilizados como aportes teóricos o texto de Walter Benjamin, acerca do narrador na obra de Nikolai Leskov, e a noção de modernidade será haurida de um trecho extraído de Marshall Bermann, em Tudo que é sólido desmancha no ar. Em relação aos aportes literários, será usada a figura de diversos contadores de estórias que surgem em obras de João Guimarães Rosa, não se fixando em uma obra definida, uma vez que o objeto de estudo configura-se basicamente como uma indagação: que faz a ancestral figura do contador de estórias em uma narrativa moderna? Estas considerações desejam oferecer trilhas, pistas, para compreender o lugar que ocupa a categoria contador de estórias nos textos de Rosa.

Em 1945-1946, quando desponta no universo literário brasileiro Sagarana, nossa crítica baliza suas reflexões tendo como parâmetro o regionalismo. Embora surgindo sob o influxo do Modernismo, movimento que pregava maiores liberdades estéticas, Sagarana é visto pela maior parte da crítica como obra de caráter intensamente regionalista. Álvaro Lins e Antonio Candido são os primeiros a outorgar-lhe caráter diferenciado, no sentido de ler naqueles contos, à primeira leitura tão regionais, tensões que serviriam como substrato para teóricos dos anos 60. Lins pontua que o tratamento estético que Rosa dispensa ao mundo animal coloca seus bois, vacas, burrinhos e pássaros no patamar de figuras literárias de alta voltagem ficcional:

Os animais dessas admiráveis histórias de Sagarana, os bois como o burrinho pedrês, agem, pensam e falam, não como os homens na maneira das fábulas e histórias da carochinha, mas como podemos imaginar, com o recurso da intuição, que eles o fariam se o autor se transportasse para dentro dos bichos, e não para lhes transmitir a sua própria personalidade, mas para interpretar e exprimir a imaginada vida interior deles. ${ }^{3}$

No entanto, apesar dessa percuciente observação, Lins resvala para o que denominaremos aqui por obsessão regionalista, que parecia estimular leituras que concebessem as obras como retratos regionais, fidedignos à terra:

Sagarana vem a ser precisamente isto: o retrato físico, psicológico e sociológico de uma região do interior de Minas Gerais, através de histórias, personagens, costumes e paisagens, vistos ou recriados sob a forma da arte de ficção. [...] Sagarana apresenta um vasto material documentário, folclórico e sociológico, já agora imprescindível para o conhecimento, mesmo científico, do interior de Minas Gerais. ${ }^{4}$

Candido destaca essa tendência de perseguir o regional entre os próprios escritores e críticos, procedendo a uma reflexão ímpar para as discussões teóricas acerca da escrita rosiana:

Natural, em meio semelhante, [referindo-se à tendência do culto à província, ao regional], o alvoroço causado pelo Sr.Guimarães Rosa, cujo livro vem cheio de "terra", fazendo arregalar os olhos aos intelectuais que não tiveram a sorte de morar ou nascer no interior

\footnotetext{
2 Por exemplo, ao afirmar-se que João Guimarães Rosa firma-se no panorama literário brasileiro como reinventor do nosso idioma, está-se reforçando um clichê, um lugar comum da fortuna crítica. Não que seja errado considerá-lo assim, uma vez que esta é uma idéia de caráter geral; no entanto, se se confinar a essa opinião, reduz-se o alcance literário da prosa rosiana.

${ }^{3}$ In: COUTINHO. Guimarães Rosa, p. 240.

${ }^{4}$ In: COUTINHO. Guimarães Rosa, p. 239-241.
} 
(digo, na "província") ou aos que, tendo nela nascido, nunca souberam do nome da árvore grande do largo da igreja, coisa bem brasileira. Seguro do seu feito, o Sr. Guimarães Rosa despeja nomes de tudo - plantas, bichos, passarinhos, lugares, modas - enrolados em locuções e construções de humilhar os citadinos. [...] Mas Sagarana não vale apenas na medida em que nos traz um certo sabor regional, mas na medida em que constrói um certo sabor regional, isto é, em que transcende a região. A província do Sr. Guimarães Rosa, - no caso Minas é menos uma região do Brasil do que uma região da arte, com detalhes e locuções e vocabulário e geografia cosidos de maneira por vezes irreal, tamanha é a concentração com que trabalha o autor. Sagarana não é um livro regional como os outros. ${ }^{5}$

Observa-se por este excerto a noção apurada que Candido teve do regionalismo de Rosa, observando que as paragens que vigoram em Sagarana congregam o local e o universal, numa tensão que a maioria dos críticos não apreendeu.

Cannabrava, em "Guimarães Rosa e a linguagem literária", em crítica a Corpo de baile, diz que Rosa buscou o dialeto brabo dos gerais:

Ele foi buscar o dialeto brabo no interior do sertão mineiro, desarticulou-o em suas partes componentes, submetendo-o a extensas manipulações lingüísticas. A frase sai pura, solta, como se viesse do fundo de sua infância livre, desembestada pelos campos gerais. [...] Não há artifício algum nessa linguagem primeva, cujas raízes se metem pela terra dura dos campos gerais. ${ }^{6}$

Neste excerto notam-se algumas incoerências. Primeiro: de que maneira o crítico entende o adjetivo brabo? Se compreendermos brabo como indomável, pleno de potencialidades, criativo, não há problemas. No entanto, se entendermos brabo como grosseiro, bruto, ignorante, seremos levados a uma espécie de valoração lingüística, acreditando que Rosa imprimiu à fala do homem dos gerais cores mais suaves, de modo a "amansar" essa fala, lapidando-a. Ora, vê-se neste ponto dois graves problemas: o localismo, conduzindo o leitor leigo a acreditar que João Guimarães Rosa quando falava sobre o homem mineiro somente se reportava ao homem mineiro, o que destrói a noção de universalidade, notada por Candido e defendida pelo escritor; e o segundo problema é o fato de que Rosa não "pegou" o dialeto brabo de sertão, fez uns ajustes e jogou nos livros. Pensar dessa maneira é ignorar a diversidade lingüística da língua portuguesa falada no Brasil e considerar como brutos os moradores do interior. Acreditamos que Cannabrava incorreu nestes erros por desconsiderar que o trabalho lingüístico a que Rosa procede sobre a matéria bruta - a língua - torna esta matéria inevitavelmente objeto estético, cujas raízes não se prendem a um solo fixo, já que a língua versada por João Guimarães Rosa é amálgama de muitos elementos e fruto de inúmeros artifícios, caso contrário não seria literatura. Ainda nessa crítica, vemos Cannabrava, talvez por amor desesperado ao menino Miguilim, afirmar que é impossível separar autor e obra, uma vez que é a substância do próprio Guimarães Rosa que corre solta nas narrativas de Corpo de baile. Tal afirmação oblitera por completo as mediações que existem entre vida e arte, realidade e literatura. Não é o próprio Rosa que está nas narrativas, nem suas lembranças infantis, mas todo um mundo ficcionalizado, eivado por uma realidade que passou pelas lentes do imaginário, recebendo tratamento estético.

\footnotetext{
${ }^{5}$ In: COUTINHO. Guimarães Rosa, p. 244.

${ }^{6}$ In: COUTINHO. Guimarães Rosa, p. 264.
} 
É evidente que há pontos positivos na crítica de Cannabrava. Quando, por exemplo, este estudioso aponta que Rosa proporciona a impressão de que os diálogos acontecem por si sós, sem a interferência de um narrador que a tudo domina, diferente de Afonso Arinos ou Monteiro Lobato. Vejamos: "A solércia de Guimarães Rosa, caboclo ladino, faz com que ele evite os tropeços e percalços de nossa literatura sertanista". ${ }^{7}$

Outra crítica interessante é de Adriano Grego. O jornal Il Tempo, de Roma, em 27 de novembro de 1956, publica a notícia intitulada "La scoperta de un capolavoro letterario che solo i Brasiliani potranno leggere", de Grego, sobre Grande sertão: veredas. Os trechos transcritos foram selecionados pelo próprio Guimarães Rosa.

Orbene, chi scrive ha l'impressione che i critici brasiliani l'abbiamo azzeccata e che si possa veramente festeggiare la nascita di un'opera narrativa potente e rivoluzionaria: qualche cosa como I'Ulysses di Joyce.[...] una lingua bizzarra, disarticolata, a volte sincopata; a volte sonora, di una efficacia sconcertante. [...] Purtroppo questo libro non sarà mai tradotto in nessuna lingua straniera, nemmeno in quelle di uguale ceppo latino. [..] I lettori italiani dovranno dunque crederci sulla parola, perchè questo lavoro non potranno leggerlo mai. [...] Il Guimarães Rosa è medico e pare si voglia dedicare, adesso, allá carriera diplomática. Ha uma facia chiusa e contegnosa. Quando lo vedi, lo scambieresti per un notaio de provincia. $^{8}$

O título da notícia - "A descoberta de um trabalho que somente os brasileiros podem ler" assinala o espanto deste crítico ao entrar em contato com o GSV e a certeza de que a referida obra jamais seria traduzida para outras línguas, ou seja, a noção de que a revolução formal instaurada por aquela narrativa não seria passível de tradução, por comportar sentidos que as outras línguas não poderiam apreender.

O crítico atribui à língua vertida em GSV os epítetos de bizarra, desarticulada, sincopada, sonora, de uma eficácia desconcertante, mas, infelizmente, de caráter intraduzível. O fecho da crítica é interessante: procede a uma breve biografia do autor, chega a descrever suas expressões faciais e arremata afirmando de modo direto que Guimarães Rosa assemelha-se a um tabelião de província, um escrivão público. 0 que Grego quis dizer com essa afirmação? Nossa leitura indica que neste pequeno fragmento ressoa algum preconceito: ele elogia, admira-se do labor literário entranhado no livro, adjetiva a língua para expressar sua profunda admiração e finaliza afirmando peremptoriamente que o autor, dono de um rosto supostamente fechado e soberbo, seria incapaz de uma explosão formal, afinal poder-se-ia confundi-lo com um tabelião de província! É uma crítica quase anedótica de tão pitoresca, na qual é possível entrever certa obsessão pela forma, ausência de reflexão crítica e uma opinião dispensável, provavelmente fruto do assombro que a leitura superficial de Rosa ocasionou.

\footnotetext{
7 In: COUTINHO. Guimarães Rosa, p. 266, grifo nosso.

8 In: BIZZARRI. João Guimarães Rosa: correspondência com seu tradutor italiano Edoardo Bizzarri (1958-1967), p. 154-155, grifo nosso.

"De modo especial, quem escreve tem a impressão de que os críticos brasileiros acertaram e que se pode realmente festejar o nascimento de uma obra narrativa potente e revolucionária, qualquer coisa como o Ulisses de Joyce. É uma língua bizarra, desarticulada, às vezes sincopada, às vezes sonora, de uma eficácia desconcertante. Infelizmente, este livro não será nunca traduzido em nenhuma língua estrangeira, nem ao menos naquelas de igual filiação latina. Os leitores italianos deverão por isso acreditar em nós, ouvir estas palavras, porque este grande trabalho, este inovador trabalho, não poderão lê-lo nunca. O Guimarães Rosa é médico e parece que deseja se dedicar, agora, à carreira diplomática. Tem um rosto fechado e soberbo. Quando o vemos, confundimo-lo com um tabelião provinciano." (tradução nossa)
} 
Mas Adriano Grego não foi o único a resvalar para esse tipo de crítica "hipnótica". No Brasil, há exemplares encomiásticos à obra de Rosa, nos quais os autores abrem mão de uma possível criticidade e procedem a elogios à forma, às inovações, à pessoa do autor, esquecendo por completo da literatura. Em suma, uma perdição nas veredas. Como textos desse tipo, podemos citar as passagens em que Franklin de Oliveira, em texto sobre Guimarães Rosa, em A literatura no Brasil, de Afrânio Coutinho, disserta sobre a vida de Guimarães Rosa:

Jamais houve brasileiro que, como João Guimarães Rosa, resguardasse com religiosa delicadeza a sua intimidade, sacrário de buscas, encontros, separações, segredos, pranto que adormece sobre si mesmo e acorda em silêncio, pauta em que nada se perde, clave em que nada é esquecido, friso em que tudo é simultâneo e desperto, efígie preservada, núcleo recôndito da vida indispersa.[...] Toda a sua vida, com a heroicidade dos santos e a santidade dos heróis - não há heroísmo sem lastro interno de contemplação - ele a sacrificou, ele a deu em holocausto à incondicional procura da beleza. ${ }^{9}$

Este excerto comprova a crítica laudatória a Rosa, mitificando-o e tornando-o distante do público, não destacando a linguagem prolixa que o crítico utilizou para explicar que o escritor não gostava de publicidade explícita em torno de sua figura. Há neste artigo de Franklin de Oliveira aspectos relevantes sobre o texto rosiano, seu processo criativo e críticas à alcunha de alienado que o autor recebeu por parte de alguns críticos.

João Guimarães Rosa afirma que muitos críticos não transpuseram a superfície das palavras: "Só o Paulo Rónai e o Antonio Candido foram os que penetraram nas primeiras camadas do derma; o resto, flutuou sem molhar as penas...". ${ }^{10}$ Regionalista em sentido amplo e, sobretudo, um contador de estórias, observa-se que Guimarães Rosa construiu um projeto estético-literário alicerçado numa concepção de língua como sistema ativo de representação da realidade. Vejamos o que diz Nunes acerca do regionalismo de Rosa:

[...] o Sertão de Guimarães Rosa coloca-se no mesmo plano da Mancha de Cervantes e da Dublin de Joyce. É o espaço que se abre em viagem, e que a viagem converte em mundo. Sem limites fixos, lugar que abrange todos os lugares, o Sertão congrega o perto e o longe, o que a vista alcança e o que só a imaginação pode ver. ${ }^{11}$

Observemos o que diz o próprio João Guimarães Rosa em entrevista a Günter Lorenz, em que o escritor expressa sua opinião a respeito de ser enquadrado no grupo de autores brasileiros regionalistas: ${ }^{12}$

[...] É necessário salientar pelo menos que entre nós o "regionalismo" tem um significado diferente do europeu.[...] Naturalmente não se deve supor que quase toda a literatura brasileira esteja orientada para o "regionalismo", ou seja, para o sertão ou para a Bahia. [...] sou regionalista porque o pequeno mundo do sertão [...] este mundo original e cheio de contrastes, é para mim o símbolo, diria mesmo o modelo de meu universo. ${ }^{13}$

É possível depreender das palavras do autor um conceito de regionalismo diverso do que surge em Afrânio Coutinho. Para Coutinho, o autor "regionalista" parece ser aquele que

\footnotetext{
${ }^{9}$ In: COUTINHO. A literatura no Brasil, p. 409-411.

${ }^{10}$ CAVALCANTE. Guimarães Rosa: ecos de uma recepção construída, p. 265.

${ }^{11}$ NUNES. O dorso do tigre, p. 174.

12 Diz Coutinho que ao grupo do documentário regionalista "deve-se juntar outra corrente de regionalistas puros, sem implicações sociais, como Guimarães Rosa" (In: COUTINHO. A literatura no Brasil, p. 275).

${ }^{13}$ In: COUTINHO. Guimarães Rosa, p. 66, grifo nosso.
} 
investe na descrição de ambientes caracteristicamente brasileiros, com ênfase na cor local e tipos humanos que vivenciam certos sentimentos não por serem humanos - homens e mulheres ficcionalizados - mas por serem sujeitos imersos em determinado espaço, que mantém com seus actantes não uma relação de mútuo engendramento de valores, mas uma relação de dominância, como se o ambiente estivesse a dizer que sua precedência sobre a personagem é mais forte que a própria ficcionalidade. Observa-se em Coutinho o regionalismo visto sob stricto senso, uma perspectiva que, ao passo que privilegia o destaque à brasilidade, exclui uma dimensão mais ampla, que está presente na concepção de Rosa e que ilustra um movimento de abertura do local para o universal, do particular para o geral, movimento este apontado por Antonio Candido, em Formação da Literatura Brasileira, como constitutivo do processo de configuração do sistema literário brasileiro, mais especificamente sentido durante a vigência da estética romântica.

Rosa considera-se um regionalista, entendendo esse termo para além de delimitações espaciais. Seu regionalismo empreende uma trajetória do sertão para o mundo; por isso o escritor alerta para o perigo de supor que "toda a literatura brasileira esteja orientada para o sertão ou para a Bahia" e pontua que é regionalista compreendendo-se que o mundo retratado em suas narrativas é o seu microcosmo, ou seja, o modelo do seu mundo, para o qual confluem suas vivências locais e universais. Em outras palavras, não é a representação do Brasil, de determinada região, que faz de Rosa um regionalista, mas sim o caráter modelar dessa representação e a explosiva tensão entre o particular e o geral que habita essa representação, esse modelo de mundo.

O uso de neologismos, o processo de açular a ressurreição de antigas palavras, a inversão de períodos, o ato de sufixar ou prefixar inesperadamente certos lexemas, transplantando processos de formação de vocábulos inerentes a uma língua para outra, constituem, em conjunto, procedimentos de subversão à forma, manifestação superficial do projeto literário rosiano.

O escritor, no projeto estético-literário ora abordado, é, antes de tudo, um contador de estórias. E contar estórias é ação que precede a literatura em sua forma escrita, relacionando-se à oralidade e à época em que um homem narrava uma estória para entender a si mesmo, ao mundo que o rodeava e transmitir o conhecimento que daí adviria. Walter Benjamim, no texto "O narrador. Considerações sobre a obra de Nikolai Leskov", comenta que $o$ ato de narrar histórias era fundamental para a constituição das gerações futuras e para a organização das experiências vividas num todo coerente e lógico, ou seja, o contador de estórias era aquele que detinha a habilidade de agregar em torno de si uma comunidade ciosa por conhecer o que o outro poderia contar, ou, ao menos, divertir-se. Os narradores dividiam-se em dois tipos arcaicos, fundamentais, que encarnam estilos de vida opostos: o Camponês Sedentário, aquele que nunca tinha saído de sua terra, mas sabia estórias de outras gerações e conseguia verbalizar as estórias que aconteciam a sua volta; e o Marinheiro Comerciante, que congregava em si estórias de longínquas regiões Às estórias ligava-se a noção de coletividade, de união de um grupo, de reunião finalisticamente orientada para um bem de caráter imaterial: a experiência. Além da comunicação da experiência, deve-se apontar que as narrativas encerravam senso prático:

[A verdadeira narrativa] tem sempre em si, às vezes de forma latente, uma dimensão utilitária. Essa utilidade pode consistir seja num ensinamento moral, seja numa sugestão prática, seja num provérbio ou numa norma de vida - de qualquer maneira, o narrador é um homem que sabe dar conselhos.[...] Aconselhar é menos responder a uma pergunta que fazer uma sugestão sobre a 
continuação de uma história que está sendo narrada.[...] O conselho tecido na substância viva da existência tem um nome: sabedoria. ${ }^{14}$

Com o advento da era industrial, a consolidação da burguesia, o advento da Imprensa e a nova forma de comunicar pautada na informação, cujo objetivo é oferecer ao público fatos empíricos, de fácil absorção, a figura do narrador é suplantada, uma vez que o coletivo cede lugar ao individual. A idéia do homem e seu grupo perde espaço para a idéia alicerçada no capitalismo selvagem do homem solitário em busca de seu próprio lugar, não importa quais os meios, uma vez que os fins justificam os meios. E dentre esses meios, o melhor é aquele que proporcionar ganhos mais rápidos. Vivenciando uma era moderna nos últimos quinhentos anos (BERMAN, 1986), o homem acredita que dispor de seu valioso tempo para aprender com experiências de tempos antigos é uma atividade inútil, uma vez que não produzirá capital. Desse modo, na época moderna, o narrador, aquele que unificava a experiência, vai fenecendo, já não é mais necessário numa sociedade em que o dinheiro compra algo mais valioso que experiência, compra a força de produção, tanto material quanto intelectual, dos sujeitos. De acordo com Benjamin, não se deve reputar o desaparecimento gradativo do narrador às características da própria modernidade:

A arte de narrar está definhando porque a sabedoria - o lado épico da verdade - está em extinção. Porém esse processo vem de longe. Nada seria mais tolo que ver nele um "sintoma de decadência" ou uma característica "moderna". Na realidade, esse processo, que expulsa gradativamente a narrativa da esfera do discurso vivo e ao mesmo tempo dá uma nova beleza ao que está desaparecendo, tem se desenvolvido concomitantemente com toda uma evolução secular das forças produtivas. (BENJAMIN, 1985, p. 201)

Se não há mais o narrador, o contador de histórias, há uma coletividade abandonada a si mesma. As pessoas não têm mais porque se reunirem, a não ser se o objetivo for a produção de um bem visível. Logo, há um embrutecimento do homem, não por estar sozinho, sem o esteio da comunidade, mas por não ter mais nenhum referencial. 0 direcionamento é, talvez, a falta de direção. Perdido, sem estórias a contar, ou melhor, com muitas estórias para contar, mas sem alguém que o faça, o sujeito inicia a travessia do eu sozinho, procurando entre fragmentos e ilusões algo que lhe pareça no mínimo coerente, unificado, à maneira de uma estória.

É no contexto de uma sociedade que vivencia um processo de modernização tardia que surge João Guimarães Rosa, imprimindo em grande parte de suas obras a figura do contador de estórias. Mas, que faz um contador de estórias em tempos modernos? É importante destacar que utilizamos moderno, ser moderno, na acepção de Berman:

Ser moderno é encontrar-se em um ambiente que promete aventura, poder, alegria, crescimento, autotransformação e transformação das coisas em redor - mas ao mesmo tempo ameaça destruir tudo o que temos, tudo o que sabemos, tudo o que somos. A experiência ambiental da modernidade anula todas as fronteiras geográficas e raciais, de classe e nacionalidade, de religião e ideologia: nesse sentido, pode-se dizer que a modernidade une a espécie humana. Porém, é uma unidade paradoxal, uma unidade de desunidade: ela nos despeja a todos num turbilhão de permanente desintegração e mudança, de luta e contradição, de ambigüidade e angústia. Ser moderno é fazer parte de um universo no qual, como diz Marx, "tudo que é sólido desmancha no ar. ${ }^{15}$

\footnotetext{
14 BENJAMIN. Magia e técnica, arte e política, p. 200.

15 BERMAN. Tudo que é sólido desmancha no ar: a aventura da modernidade, p. 15.
} 
Estará ele deslocado, tão perdido quanto seu público? Observemos o que diz o autor quando solicitado a falar sobre o processo de escrever em relação a sua vida:

[...] nós, os homens do sertão, somos fabulistas por natureza. Está no nosso sangue narrar estórias; já no berço recebemos esse dom para toda a vida. Desde pequenos, estamos constantemente escutando as narrativas multicoloridas dos velhos, os contos e lendas, e também nos criamos em um mundo que às vezes pode se assemelhar a uma lenda cruel. Deste modo a gente se habitua e narrar estórias corre por nossas veias e penetra em nosso corpo, em nossa alma, porque o sertão é a alma de seus homens. [...] No sertão, o que pode uma pessoa fazer do seu tempo livre a não ser contar estórias? A única diferença é simplesmente que eu, em vez de contá-las, escrevia. [...] disse a mim mesmo que sobre o Sertão não se podia fazer "literatura" do tipo corrente, mas apenas escrever lendas, contos, confissões. ${ }^{16}$

O sustentáculo do projeto estético-literário de Rosa é a idéia encarnada na figura do contador de estórias. Como o próprio autor pontua, a única diferença reside tão somente no procedimento do contar: ele escreve o que é matéria de contação, imprimindo à oralidade marcas da língua escrita. De acordo com Vargas Llosa (2004), em "A verdade das mentiras", os fatos, ao serem narrados, sofrem cabal modificação, cuja responsável é a linguagem. No caso de Guimarães Rosa, temos os fatos que percorrem uma longa travessia até serem metamorfoseados pela linguagem escrita - primeiro, o acontecimento está disperso, a intuição do contador capta esse acontecimento e procura unificá-lo sob a forma de estória oral, depois, surge a figura híbrida do escritor/contador numa sociedade moderna, que transforma os acontecimentos orais em estórias escritas, tendo agora um constructo literário em que pulsam séculos de tradição oral em consonância com a linguagem escrita, ambas interagindo no reagente objeto que é a narrativa literária.

Em "Buriti", de Noites do sertão, apontamos a figura da rezadeira Dô-Nhã, cujo verdadeiro encanto não está necessariamente nas rezas que profere, mas nas estórias que carrega. Mulher que fora casada com quatro homens e com todos vivera em perfeita harmonia, Dô-Nhã chega à fazenda do Buriti-Bom para lançar um feitiço de amarração amorosa - trazer o homem de Lalinha mediante palavras de encantamento. Observemos a descrição da personagem:

Conforto que era para a gente dela se rir, aquela mulherota, de curta cara arrendondante, com uma pinta de verruga pondo um buquê de pêlos; os cabelos por cima numa bola se atufando; ela séria, séria demais, de propósito; e como fungava.[...] Jocosa, toda falava, relafava e perguntava, em mestra naturalidade - e assim era um denunciar-se de ter saído de uma comédia, era, pois. ${ }^{17}$

Antes de rezadeira, Dô-Nhã é uma contadora de estórias. As pessoas da fazenda reúnem-se para ouvi-la, conhecer sua pitoresca estória que é sua própria vida e que encanta, porque vai além dos limites comuns, ultrapassa a moral estabelecida, obedecendo à moral do sertão - uma mulher e seus homens: "Eu estava com dó dêles. Decidimos d'êles todos quatro ficarem comigo... Assim completo, durou dois anos...". ${ }^{18}$ Ao final, a rezadeira não tem mais nenhum marido, concluindo com uma frase bem moderna: "Este mundo é diabrável para consumir gente...". ${ }^{19}$ Num mundo que consome as pessoas, somente restam

${ }^{16}$ COUTINHO. Guimarães Rosa, p. 69, grifo nosso.

17 ROSA. Noites do sertão, p. 162.

${ }^{18}$ ROSA. Noites do sertão, p. 162.

${ }^{19}$ ROSA. Noites do sertão, p. 169. 
as estórias, uma forma de sobreviver a essa diabrável tendência. É necessário destacar o ambiente em que Dô-Nhã aparece. Exatamente no mundo da fazenda Buriti Bom, um mundo fechado, limitado, pequeno, feudal, que sofre certo abalo com a chegada da personagem Lalinha, elemento transplantado da cidade para o interior, um local fora do comum, um mundo que, apesar de viver por leis antigas, com um patriarca que a tudo rege - Iô-Liodoro - proporciona liberdade aos sentidos de seus moradores. Vejamos como é caracterizado o Buriti Bom: "Mas o Buriti Bom era um belo pôço parado. Ali nada podia acontecer, a não ser a lenda". ${ }^{20}$ Portanto, não é por acaso que Do-Nhã e seu caso de poligamia surge nesta narrativa.

Outro contador que podemos apontar é o pequeno Miguilim e suas estórias inconclusas, de Campo Geral. Há ainda Riobaldo, Grande sertão: veredas, o clássico contador de estórias, com uma frase que consideramos emblemática de todo ato de contar uma estória: "O que lembro, tenho" Diz João Guimarães Rosa acerca dessa oração: "Riobaldo quer dizer que a memória é para ele uma posse do que ele viveu, confere-lhe propriedade sobre as vivências passadas, sobre as coisas vividas" (in: MEYER-CLASON, 2003, p. 114).

Em "Cara-de-bronze" temos o vaqueiro Grivo e a viagem que empreende a mando do fazendeiro Segisberto Géia para trazer contado o "quem das coisas". "Cara-de-bronze" é uma novela eivada de recursos teatrais e cinematográficos, destacando-se entre as narrativas de Corpo de baile por apresentar artifícios que nos permitem entrever até três ou quatro ou mais micro-narrativas. Focalizaremos a figura do Grivo. Esta personagem já surge em "Campo Geral", como menino pobre. E no próprio "Campo Geral" há um embrião de Grivo, quando o menino Dito contrai tétano e pede que Miguilim vá se inteirar dos "acontecimentos" que tecem seu cotidiano de criança: "Miguilim queria ficar sempre perto, mas o Dito mandava ele fosse saber todas as coisas que estavam acontecendo. - 'Vai ver como é que o mico está' [...] o Dito gostava de ter notícia de todas as vacas, de todos os camaradas que estavam trabalhando nas outras roças, enxadeiros que meavam" (ROSA, 2001, p. 112).

O fazendeiro Cara de bronze, cujo apelido nos remete ao material, o bronze, misterioso, metal que não tem a glória do ouro e da prata, mas que serve para forjar armas, está confinado a um quarto, doente, talvez à beira da morte, e seleciona um vaqueiro que possa Ihe trazer a poesia dispersa do ambiente. Vemos este fazendeiro como metáfora do patriarcado em decadência. Cara de bronze não tem filhos, é uma potência que não engendrou nada além de uma fazenda. Dele, os outros vaqueiros fazem um mosaico discursivo. É um personagem construído mediante retalhos. Bronze. Compreendemos Grivo como um clássico contador de estórias, porque ele tem por função reunir detalhes dispersos, como o nome de plantas e de pássaros, a visão da rede de uma mulher, a "Muito Branca-de-Todas-as-Cores", e oferecer estes detalhes ao Cara de bronze, que está dentro de um universo fechado, o quarto, para, quem sabe, perpetuar-lhe a existência.

Concluímos este breve artigo destacando que a figura do contador de estórias em Rosa surge geralmente dentro de situações narrativas. As estórias não surgem para ser julgadas. Às vezes, aparecem como narrativas exemplares, como, por exemplo, o caso da Maria Mutema, em GSV, para comprovar que o mal pode sim transformar-se em bem, ou mesmo para demonstrar que todas as fronteiras são tênues - bem e mal, amor e ódio pois dependem da perspectiva. ${ }^{21}$ Os contadores de estória rosianos agregam coletividades, repassam alguma sabedoria, e perpetuam a vida.

\footnotetext{
20 ROSA. Noites do sertão, p. 176.

${ }^{21}$ A atitude da personagem Maria Mutema é a da maldade gratuita, sem um fim determinado: ela assassina o marido despejando chumbo derretido em seu ouvido, sem aparente motivo. A seguir,
} 


\section{Abstract:}

This paper aims to study the story teller in the aesthetic-literary project of Guimarães Rosa. For this, we will briefly review Rosa's critical, highlighting clichés for, then get further in aspects of this project, as a peculiar notion of regionalism of this author, his work with the language and figure of the story teller, of oral matrix, which we shall interprete him as a narrator who acts in modern times. We use the figure of several story tellers that appear in works of João Guimarães Rosa, especially in the novels "Buriti" and "Cara-de-bronze". Our object of study is basically configured as a question: what does the ancestral figure of the story teller do in a modern narrative? Our observations wish to offer trails, tracks, to understand the place held by the category of story teller in the texts of Rosa, which comes from oral literature.

Keywords: João Guimarães Rosa; language; story.

Referências

BENJAMIN, W. Magia e técnica, arte e política. Trad. Sergio Paulo Rouanet. São Paulo: Brasiliense, 1985.

BERMAN, M. Tudo que é sólido desmancha no ar: a aventura da modernidade. Trad. Carlos Felipe Moisés; Ana Maria L. Ioriatti. São Paulo: Companhia das Letras, 1986.

BIZZARRI, E. João Guimarães Rosa: correspondência com seu tradutor italiano Edoardo Bizzarri (1958-1967). Rio de Janeiro: Nova Fronteira, 2003.

CANDIDO, Antonio. Formação da Literatura Brasileira. 7. ed. Belo Horizonte: Itatiaia, 1993, 2 v.

CAVALCANTE, N. Guimarães Rosa: ecos de uma recepção construída. O Eixo e a Roda. UFMG, Belo Horizonte, v. 12, 2006. Disponível em: <http://www.letras.ufmg.br/poslit>. Acesso em: 21 jun. 2008.

COUTINHO, Afrânio. A literatura no Brasil. 3. ed. Rio de Janeiro: J. Olympio, 1986.

COUTINHO, Eduardo F. (Org.) Guimarães Rosa. 2. ed. Rio de Janeiro: Civilização Brasileira/INL, 1991. (Coleção Fortuna Crítica 6).

MEYER-CLASON, C. João Guimarães Rosa: correspondência com seu tradutor alemão. (1958-1967). Rio de Janeiro: Nova Fronteira, 2003.

NUNES, B. O dorso do tigre. São Paulo: Perspectiva, 1969.

ROSA, João Gumiarães. Manuelzão e Miguilim. Rio de Janeiro: Nova Fronteira, 2001. . Noites do sertão. Rio de Janeiro: Nova Fronteira, 2001. . Noites do sertão. Rio de Janeiro: J. Olympio, 1965.

induz o Padre Ponte à morte, justificando que assim procedera por muito the amar, depois, confirma que mentira. Razões? Não existem. É a ação indubitável do Mal, a personificação do monstruoso, do desagradável, do incompreensível que não se pode explicar. No entanto, ela se redime. E o povo perdoa. O sofrimento de Maria Mutema é a sua salvação, pois de alguma maneira obscura oferece ao povo ao menos uma justificativa para tantos crimes. Ora, sofrimento e culpa, no imaginário popular, são as ante-salas do paraíso. Logo, Maria Mutema, assassina, cede lugar à Maria Mutema, santa. 
. No Urubuquaquá, no Pinhém. Rio de Janeiro: Nova Fronteira, 1984.

VARGAS, L. M. A verdade das mentiras. Trad. Cordelia Magalhães. São Paulo: Arx, 2004. 